\title{
Innovación en la gestión de lodos generados en plantas de tratamiento de aguas residuales de origen doméstico en Lima- Perú
}

\author{
Innovation in the management of sludge generated in domestic waste water \\ treatment plants in Lima - Peru
}

\author{
José Jorge Espinoza Eche1, Eulogio Guillermo Santos de la Cruz²
}

Recibido: 18/08/2021 - Aprobado: 24/09/2021 - Publicado: 23/12/2021

\begin{abstract}
RESUMEN
En las 7 plantas de tratamiento de aguas residuales de origen doméstico evaluadas, ubicadas en diferentes distritos de Lima Metropolitana, se generan $2537,85 \mathrm{Tn} / \mathrm{dí}$ de lodos con alto contenido de humedad, convirtiéndose en un problema dado que los espacios para su confinamiento son escasos. Para evaluar su transformación en insumo, se procedió a caracterizar física-química y biológicamente los lodos, lo cual se hizo en dos oportunidades, y se comparó los resultados con los límites máximos permisibles establecidos en la norma peruana, mexicana y de la Environmental Protection Agency. Con la finalidad de cuantificar su potencial nutricional, se determinó los contenidos porcentuales de pH, materia orgánica, nitrógeno, fósforo y potasio los cuales fueron comparados con los resultados de calidad del compost que se elabora en la Planta de Pampamarca Chico-Carhuaz. Los resultados arrojaron exceso concentraciones de Cadmio, Zinc y Coliformes Termotolerantes, en lo lodos generados en las plantas de Huascar, J.C. Tello y San Juan. Respecto a contenidos nutricionales, todos tienen altas concentraciones de Nitrógeno y Materia Orgánica, y $\mathrm{pH}$ aceptable. Para determinar la demanda para uso con fines agrícolas o energéticos se realizaron sendas encuestas obteniendo como resultados que: para lo primero, existe un requerimiento potencial; para lo segundo, se requiere aplicar estrategias para ofertarlo. Convertir el lodo en insumo requiere recursos financieros que se pueden obtener innovando la gestión actual.
\end{abstract}

Palabras claves: Lodos crudos; insumo; fertilizantes; valoración energética; innovación.

\begin{abstract}
In the 7 domestic wastewater treatment plants evaluated, located in different districts of Metropolitan Lima, $2537.85 \mathrm{Tn} /$ day of sludge with high moisture content are generated, becoming a problem given that the spaces for its confinement are scarce. To evaluate its transformation into an input, the sludge was physically-chemically and biologically characterized, which was done twice, and the results were compared with the maximum permissible limits established in the Peruvian, Mexican and Environmental Protection Agency regulations. In order to quantify its nutritional potential, the percentage contents of $\mathrm{pH}$, organic matter, nitrogen, phosphorus and potassium were determined, which were compared with the quality results of the compost produced at the Pampamarca Chico-Carhuaz Plant. The results showed excess concentrations of Cadmium, Zinc and Thermotolerant Coliforms, in the sludge generated in the Huascar, J.C. Tello and San Juan. Regarding nutritional content, they all have high concentrations of Nitrogen and Organic Matter, and an acceptable $\mathrm{pH}$. To determine the demand for use for agricultural or energy purposes, surveys were carried out, obtaining the results that: for the first, there is a potential requirement; for the second, it is necessary to apply strategies to offer it. Converting the sludge into an input requires financial resources that can be obtained by innovating the current management.
\end{abstract}

Keywords: Raw sludge; input; fertilizers; energy valuation; innovation.

\footnotetext{
1 Universidad Nacional Mayor de San Marcos, Facultad de Ingeniería Geológica, Minera, Metalúrgica y Geográfica, Lima, Perú. Docente, Ingeniero Sanitario. Autor para correspondencia: jespinozae@unmsm.edu.pe - ORCID: https://orcid.org/0000-0001-6296-1147

2 Universidad Nacional Mayor de San Marcos, Facultad de Ingeniería Industrial, Lima, Perú. Docente, Ingeniero Industrial. E-mail: esantosd@unmsm.edu.pe - ORCID: https://orcid.org/0000-0003-3434-7865
} 


\section{INTRODUCCIÓN}

Actualmente en el Perú, 164 localidades, de un total de 253 administradas por Empresas Prestadoras de Servicios de Saneamiento -EPS-, disponen todo o parte de sus aguas residuales recolectadas en los sistemas de alcantarillado sanitario en plantas de tratamiento de aguas residuales. Esto representa una atención a nivel nacional de 14'083,000 habitantes que generan 2'293,000 m³/día de aguas residuales. En las 7 plantas de tratamiento de aguas residuales de origen doméstico-PTAR (SUNASS, 2015), que administra el Servicio de Agua Potable y Alcantarillado de Lima -SEDAPAL- ubicadas en: Ventanilla y Ancón, al norte de Lima Metropolitana, y San Juan, Julio C. Tello, Cieneguilla, Huáscar y José Gálvez ubicadas al sur de nuestra ciudad capital. Se tratan $81630,72 \mathrm{~m}^{3} /$ día de aguas residuales y se generan $2537,85 \mathrm{Tn} /$ día de lodos con alto contenido de humedad convirtiéndose en un problema dado que los espacios para su confinamiento son escasos y/o que las distancias existentes desde los centros de generación hasta los lugares de disposición final son significativas. Cabe resaltar que SEDAPAL es la única empresa que se preocupa en disponer adecuadamente este desecho en rellenos sanitarios.

Innovar la gestión de lodos generados en plantas de tratamiento de aguas residuales de origen doméstico en Lima-Perú.

- La innovación de la gestión permite la conversión en un insumo al mejorar la calidad de los lodos generados en plantas de tratamiento de aguas residuales de origen doméstico en Lima-Perú.

- La innovación de la gestión contribuye a la comercialización al adquirir valor comercial los lodos tratados generados en plantas de tratamiento de aguas residuales de origen doméstico en LimaPerú (SUNASS, 2015).

\section{MÉTODOS}

\subsection{Pre-campo}

Se tomó nota de los procesos y operaciones que se llevan a cabo en las 7 PTAR muestra, identificando los procedimientos que propician la generación de lodos, el manejo y resultados obtenidos. En la Tabla 1 se anotan los distritos donde está ubicada cada PTAR, todas ubicadas en Lima Metropolitana, el destino de la descarga de aguas residuales tratada y la cantidad de lodos generados.

Se llevaron a cabo entrevistas a personas con conocimiento del tema, con la finalidad de tomar conocimiento sobre la gestión de los lodos. También se diseñó dos fichas de encuesta: una para medir el nivel de utilización con fines agrícolas, ya que se identificó personas que hacen uso informal de estos lodos; y la otra para establecer la utilidad del lodo con fines de generación de energía. En Anexo 1 se adjuntas las fichas elaboradas.

\subsection{Trabajo en campo \\ 2.2.1 Caracterización del lodo crudo}

Se tomo una muestra en cada PTAR del lodo crudo, en dos oportunidades diferentes, con la finalidad de establecer sus características físicas, químicas y biológicas. Con la finalidad de determinar el potencial del lodo como producto a utilizar en agricultura, se realizó la determinación de concentración de los parámetros: pH, Materia Orgánica, Nitrógeno Total, Fósforo y Potasio disponible. A continuación, se describe la metodología usada.

\section{a. Materiales}

- Recipientes y/o pipetas

- Bolsas de plástico con cierre hermético (ciplot) de aprox. $100 \mathrm{ml}$

- Guantes de vinil y mascarilla

- Etiquetas y plumón delgado de tinta indeleble

- Botellas de vidrio esterilizadas, de cuello ancho y de 500 a 1000 gr de capacidad

- Fichas de encuestas

\section{b. Procedimientos de toma y preparación de muestras}

Se tomaron muestras de lodos secos considerando lo siguiente:

Tabla 1. Muestras del trabajo de investigación

\begin{tabular}{|c|c|c|c|}
\hline $\mathbf{N}^{\circ}$ & Denominación del sistema & Punto de descarga & Generación de lodos (Tn/año) \\
\hline 1 & $\begin{array}{l}\text { PTAR San Juan } \\
\text { Distrito San Juan de Miraflores }\end{array}$ & $\begin{array}{l}\text { Vertimiento al mar } \\
\text { Reuso }\end{array}$ & 2440,00 \\
\hline 2 & $\begin{array}{l}\text { PTAR Julio C. Tello } \\
\text { Distrito Lurín }\end{array}$ & $\begin{array}{l}\text { Vertimiento al Río Lurín } \\
\text { Reuso }\end{array}$ & 806,12 \\
\hline 3 & $\begin{array}{l}\text { PTAR Cieneguilla } \\
\text { Distrito Cieneguilla }\end{array}$ & $\begin{array}{l}\text { Vertimiento al Río Lurín } \\
\text { Reuso }\end{array}$ & 87,69 \\
\hline 4 & $\begin{array}{l}\text { PTAR Ancón } \\
\text { Distrito Ancón }\end{array}$ & Vertimiento al mar & 236,29 \\
\hline 5 & $\begin{array}{l}\text { PTAR Ventanilla } \\
\text { Distrito Ventanilla }\end{array}$ & $\begin{array}{l}\text { Vertimiento al mar } \\
\text { Reuso }\end{array}$ & 7499,70 \\
\hline 6 & $\begin{array}{l}\text { PTAR Huáscar } \\
\text { Distrito Villa El Salvador }\end{array}$ & Reuso & 180,22 \\
\hline 7 & $\begin{array}{l}\text { PTAR José Gálvez } \\
\text { Distrito Villa María del Triunfo }\end{array}$ & Reuso & 187,00 \\
\hline
\end{tabular}

Fuente: Elaboración propia. 
- Homogenización de muestras, utilizando recipientes y/o pipetas adecuadas se recogieron muestras parciales de diferente edad de lodo. Se mezclaron adecuadamente con la finalidad de obtener una mezcla homogénea.

- Cuando las muestras se tomaron en diferentes lugares se consideraron cantidades variables de 5 $\mathrm{Kg}$ a $10 \mathrm{Kg}$, para al momento de homogenizar seleccionar una de mínimo $5 \mathrm{~kg}$.

- Las muestras seleccionadas se echaron en bolsas plásticas convenientemente hermetizadas, evitando en lo posible que se calienten.

- Se anotaron los datos básicos: fecha y lugar de muestreo, y se remitieron al laboratorio EQUAS SA para realizar los análisis correspondientes.
- Las muestras se mantuvieron refrigeradas a $4^{\circ} \mathrm{C}$ hasta el análisis.

En la Tabla 2 se anotan las fechas de monitoreo y las coordenadas geográficas donde se tomaron las muestras de lodos, en cada PTAR.

\section{c. Métodos de análisis en laboratorio}

Se aplicaron los métodos de análisis establecidos por la Environmental Protection Agency -EPA- que se detallan en la Tabla 3 .

\subsubsection{Medición de demanda de lodo tratado}

Con la finalidad de medir la demanda para usos con fines de fertilizar suelos, considerando el lodo crudo tratado, se

Tabla 2. Puntos de muestreo de lodos

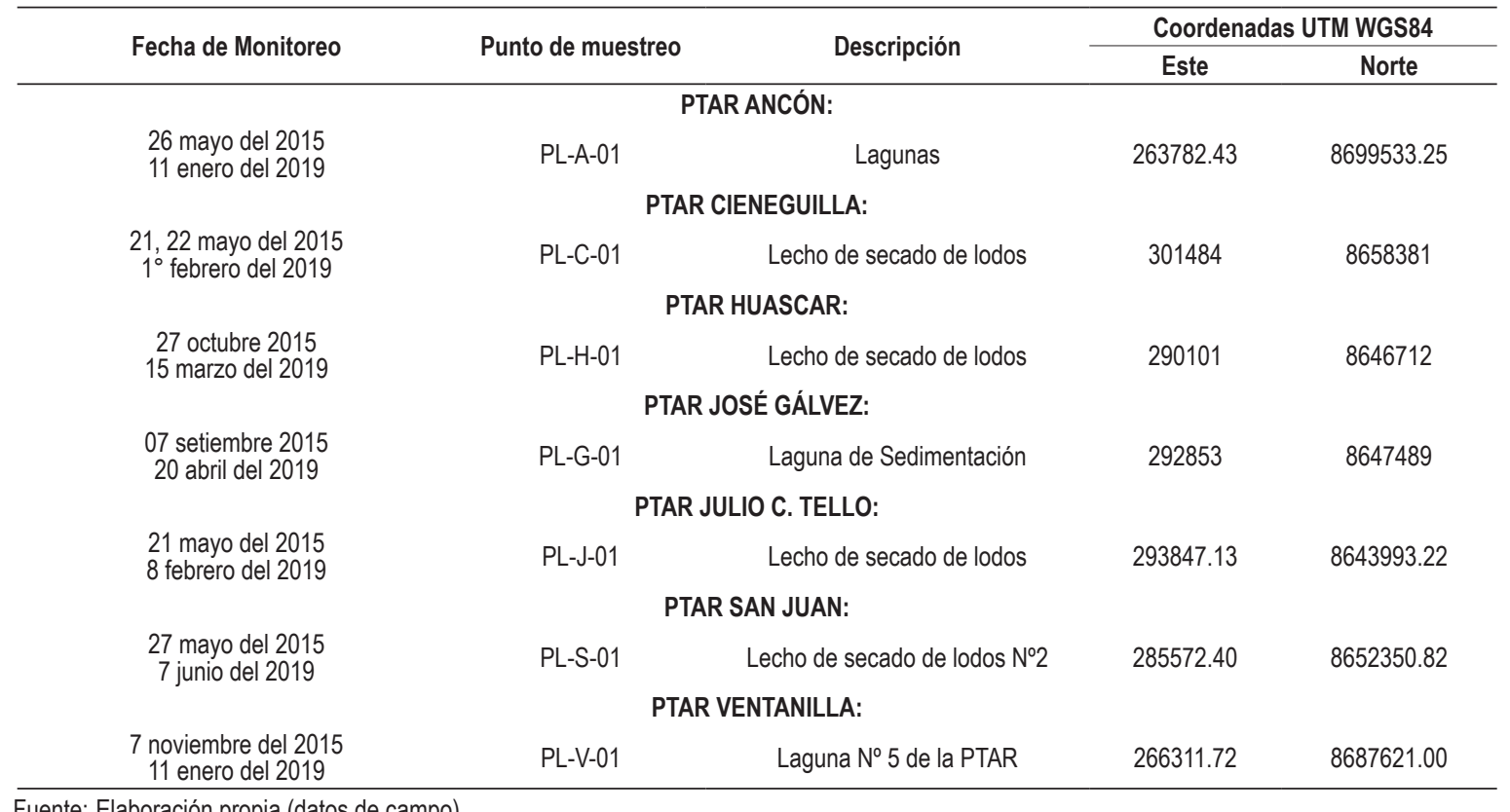

Fuente: Elaboración propia (datos de campo)

Tabla 3. Métodos de análisis de muestras de lodos

\begin{tabular}{|c|c|c|}
\hline Parámetro & Método de Análisis & Especificación \\
\hline \multicolumn{3}{|l|}{ Físico - Químico y Biológico } \\
\hline Sólidos totales & SM-2540 B & Secado a $105^{\circ} \mathrm{C} \pm 5^{\circ} \mathrm{C}$ \\
\hline Sólidos volátiles & SM-2540 E & Calcinación a $550^{\circ} \mathrm{C}$ \\
\hline $\mathrm{pH}$ & SW-9045 & Suspensión y determinación potenciométrica \\
\hline Conductividad eléctrica & SW-9050 & Determinación por conductivimetría \\
\hline Materia orgánica & & Calcinación a $550^{\circ} \mathrm{C}$ \\
\hline $\mathrm{Al}, \mathrm{Ag}, \mathrm{As}, \mathrm{Ba}, \mathrm{Be}, \mathrm{Cd}, \mathrm{Co}, \mathrm{Cr}, \mathrm{Cu}, \mathrm{Fe}, \mathrm{Mn}, \mathrm{Mo}, \mathrm{Ni}, \mathrm{Pb}, \mathrm{Sb}, \mathrm{Se}$ y Sn, Bi, $\mathrm{Hg}, \mathrm{N}, \mathrm{P}, \mathrm{K}$ & EPA 6010 & Técnica del horno de grafito o electrotérmica \\
\hline Coliformes Termotolerantes & Métodos Estándar 9221 A, 1995 & Método de recuento por dilución en tubo \\
\hline Salmonella spp. & \multicolumn{2}{|c|}{ Métodos Estándar 9260 D, 1992} \\
\hline Huevos de Helmíntos & \multicolumn{2}{|l|}{ NOM-AA-113-SECOFI-1999 } \\
\hline \multicolumn{3}{|c|}{ Nutricional: } \\
\hline $\mathrm{pH}$ & \multicolumn{2}{|c|}{ Método potenciómetro: relación suelo agua 1:1 (acides y alcalinidad del suelo) } \\
\hline Porcentaje de materia Orgánica & \multicolumn{2}{|c|}{ Método de Walkley y Black } \\
\hline Nitrógeno $(\mathrm{N})$ total & \multicolumn{2}{|l|}{ \% de Materia Orgánica (M.O) x 0.05} \\
\hline Fósforo $(\mathrm{P})$ disponible & \multicolumn{2}{|c|}{ Método de Olsen Modificado. Extracto de $\mathrm{NaHCO}_{3} 0.5 \mathrm{M}$, pH 8.5} \\
\hline Potasio $(\mathrm{K})$ disponible & \multicolumn{2}{|c|}{ Método del ácido sulfúrico 6N y/o con Acetato de Amonio pH 7.0} \\
\hline
\end{tabular}

Fuente: Elaboración propia 
aplicó una encuesta muestral aleatoria, de 10 preguntas, a 100 familias dedicadas a la agricultura; las áreas de aplicación fueron seleccionadas de acuerdo a la ubicación potencial de clientes del futuro mercado consumidor de este producto, siendo estas los alrededores de las PTAR San Juan y PTAR José Gálvez de los distritos de San Juan de Miraflores y Villa María del Triunfo respectivamente, debido a que la población asentada en estas zonas se dedica a la siembra de diversas especies ornamentales. También se aplicó 9 fichas de encuestas a 7 empresas cementeras y 2 ladrilleras para medir la necesidad de uso del lodo con fines de generación de energía.

\subsection{Post- campo}

Los resultados físicos, químicos y bacteriológicos, obtenidos del análisis de laboratorio, fueron sistematizados, graficados y comparados con los límites máximos permisibles -LMP- de la norma peruana, mexicana y EPA. La Norma Peruana, DS N 015-2017-VIVIENDA, considera 2 clases de lodos, Clase A: aquellos aplicables al suelo sin restricciones sanitarias; Clase B: aquellos aplicables al suelo con restricciones sanitarias según localización de los suelos y/o tipo de cultivos; los LMP se pueden apreciar en Anexo 2 - Tabla 1.

La Norma Oficial Mexicana NOM-004SEMARNAT-2002, considera 3 clases de calidad de lodos y para cada uno de ellos establece límites máximos permisibles que son los que se muestran en Anexo 2 Tabla 2, cada clase corresponde a un tipo de tratamiento específico de lodos, como en el Perú el tratamiento de lodos es incipiente o no existe para el caso de esta Norma se ha seleccionado los límites contenidos en la categoría más baja y que corresponde a la Clase $\mathrm{C}$; asimismo, para determinar el tipo de aprovechamiento de los Biosólidos, lodos con hasta un $85 \%$ de contenido de humedad, se especifica lo que se aprecia en Anexo 2 - Tabla 3.

Respecto a la Norma de la Environmental Protection Agency EPA 40CFR-503 PC-EQ QUALITY, las clases de tipos de tratamiento específico de lodos corresponden a los aprovechamientos señalados en Anexo 2 - Tabla 4.

Los resultados de las concentraciones nutricionales de los lodos fueron comparados con las concentraciones que se obtiene de uno de los compost de más alta calidad que se obtiene en el Perú y que provienen del relleno sanitario de Carhuaz (Huaraz) y que se pueden observar en Anexo 2 - Tabla 5.

\section{RESULTADOS}

\subsection{Indicadores operativos de las PTAR}

La gestión de este desecho irroga costos ya que SEDAPAL tiene que contratar una Empresa Operadora de Residuos Sólidos a la cual le paga para que se encargue de almacenar, ver fotografía 1, y transportar estos lodos hacia alguno de los rellenos sanitarios existentes en la ciudad a un costo diario de S/ 248,724. Como lo que se pretende es innovar la gestión con la finalidad de posibilitar el tratamiento de los lodos crudos, es decir convertirlo en un insumo, para luego comercializarlos, es que necesitamos tener indicadores operativos que nos posibiliten ello.

Entre los indicadores operativos más resaltantes se señalan tres: a) tipo de tratamiento actual de lodos, en 5 de las 7 PTAR muestra se realiza el secado físico en lechos, la que no es tan efectivo dado el clima que predomina en Lima Metropolitana, en las otras 2 se deshidratan los lodos usando máquinas centrifugadoras; b) relación lodo/agua, son los lodos de la PTAR San Juan los que tienen porcentaje significativo de esta relación lo que implica una mayor generación de lodos; c) relación área/personal, importante para determinar la necesidad de personal que se dedique exclusivamente al tratamiento de lodos, cabe anotar que no se tiene actualmente personal específico para el manejo de lodos. En la Tabla 4 se anotan estos indicadores.

\subsection{Cantidad de lodos crudos}

En total, sumando la generación de lodo en las 7 PTAR, la cantidad es de 926 315,19 Tn/Año (2 537,85 Tn/día) que es equivalente a $899335,13 \mathrm{~m}^{3} /$ año. En la PTAR que se generó mayor cantidad de lodo fue en San Juan (7.944\% respecto al caudal tratado) que tiene tecnología tipo Lagunas Aireadas. Cabe resaltar que en esta planta se ha tenido que reducir el caudal tratado justamente por el exceso de generación de lodos. La PTAR de menor generación de lodo ha sido la de Cieneguilla (0.004\%) la única cuyo tipo de tratamiento de aguas residuales es Lodos Activados. En ambos casos los lodos se deshidratan en lechos de secado.

Tabla 4. Indicadores operativos de gestión de lodos

\begin{tabular}{|c|c|c|c|c|c|}
\hline \multirow{2}{*}{ PTAR } & \multicolumn{2}{|c|}{ Cantidad operacional } & \multirow{2}{*}{ Tipo Tratamiento Lodos } & \multirow{2}{*}{ Relación Lodo/Agua (\%) } & \multirow{2}{*}{$\begin{array}{l}\text { Relación } \\
\text { Área/Personal } \\
\text { (Ha/Operador) }\end{array}$} \\
\hline & (Tn/año) & $\left(m^{3} / a n ̃ o\right) *$ & & & \\
\hline Ancón & 236,26 & 229,38 & D & 0.018 & 2,37 \\
\hline Cieneguilla & 87,89 & 85,33 & LS & 0.004 & 0,82 \\
\hline Julio C. Tello & 806,12 & 782,64 & LS & 0.117 & 0,79 \\
\hline San Juan & 917318,00 & 890600,00 & LS & 7.944 & 4,86 \\
\hline José Gálvez & 187,00 & 181,55 & LS & 0.006 & 0,91 \\
\hline Huáscar & 180,22 & 174,97 & LS & 0.006 & 1,38 \\
\hline Ventanilla & 7499,70 & 7281,26 & $\mathrm{D}$ & 0.085 & 1,97 \\
\hline TOTAL & 926315,19 & 899335,13 & & & \\
\hline
\end{tabular}

Fuente: Elaboración propia en base a resultados obtenidos.

Notas: ${ }^{*}$ ) Según la Norma Técnica OS 090 se considera que la densidad del lodo es de $1.03 \mathrm{Tn} / \mathrm{m}^{3}, \mathrm{D}=$ deshidratación, LS = lechos de secado. 


\subsection{Caracterización de lodos crudos}

Con la finalidad de establecer calidad de los lodos crudos, de las 7 PTAR, los resultados de su caracterización se compararon con las normas mexicana, EPA y peruana. Respecto a contenidos metálicos en exceso: según la norma mexicana el Cadmio del lodo generado en la PTAR J.C. Tello esta por encima de los LMP; mientras que el Zinc del lodo generado en la PTAR San Juan excede según la norma EPA y peruana; el resto de los parámetros no excede los LMP. Referente a contenidos biológicos, teniendo en cuenta las 3 normas consideradas, el exceso de coliformes termo tolerantes se aprecia en las PTAR: Huáscar, J.C. Tello y San Juan. Los lodos crudos generados en las otras PTAR (Ancón, Cieneguilla, José Gálvez y Ventanilla) pueden tener: usos forestales, para mejoramiento de suelos o agrícolas (según la norma mexicana); recuperación de suelos, plantaciones forestales, consumos no directos o coberturas de rellenos sanitarios (según norma EPA); usarse con restricciones sanitarias (según la norma peruana). En la Tabla 5 se resumen lo señalado.

\subsection{Calidad comercial de los lodos \\ a. Uso como fertilizante}

Las concentraciones, en porcentaje, obtenidas de componentes nutricionales del lodo crudo se compararon con las concentraciones del compost obtenido en Carhuaz (CONAM, 2006). En la Tabla 6 se resumen los resultados.

\section{b. Valor energético}

Con la finalidad de determinar parcialmente el potencial energético de los lodos de las PTAR San Juan y Ventanilla, se evaluó: contenido de humedad, material volátil, cenizas, carbono fijo y poder calorífico. Este último se determinó teóricamente aplicando la fórmula de Gouthal, En la Tabla 7 se observan los resultados obtenidos de poder calorífico de los lodos crudos.

Tabla 5. Resumen de evaluación de calidad de lodos de las 7 PTAR

\begin{tabular}{|c|c|c|c|c|c|c|}
\hline \multirow{2}{*}{ PTAR } & \multicolumn{3}{|c|}{ Contenido Metálico } & \multicolumn{3}{|c|}{ Contenido Biológico } \\
\hline & N. México & EPA & DS. 015-2014-V & N. México & EPA & DS. 015-2014-V \\
\hline Ancón & Excelente & $\sqrt{ }$ & $\sqrt{ }$ & C & B & B \\
\hline Cieneguilla & Excelente & $\sqrt{ }$ & $\sqrt{ }$ & C & B & B \\
\hline Huáscar & Excelente & $\sqrt{ }$ & $\sqrt{ }$ & Exceso CTt & Exceso CTt & Exceso CTt \\
\hline J. Gálvez & Excelente & $\sqrt{ }$ & $\sqrt{ }$ & $\mathrm{C}$ & B & B \\
\hline J. C. Tello & Excede $\mathrm{Cd}$ & $\sqrt{ }$ & $\sqrt{ }$ & Exceso CTt & Exceso CTt & Exceso CTt \\
\hline San Juan & Bueno & Excede $\mathrm{Zn}$ & Excede Zn & Exceso CTt & Exceso CTt & Exceso CTt \\
\hline Ventanilla & Excelente & $\sqrt{ }$ & $\sqrt{ }$ & C & B & B \\
\hline
\end{tabular}

Fuente: Elaboración propia. Notas. - C= Usos forestales, mejoramiento de suelos, usos agrícolas; $\mathrm{CTt}=$ Coliformes termotolerantes; $\mathrm{B}$ (EPA)= Recuperación de suelos, plantaciones forestales, consumos no directos, cobertura de rellenos sanitarios; $\mathrm{B}$ (Perú) $=$ Con restricciones sanitarias; No excede los LMP $=\sqrt{ }$.

Tabla 6. Caracterización de lodos considerando potencial para uso en fertilidad de suelos

\begin{tabular}{|c|c|c|c|c|c|c|c|}
\hline \multirow{3}{*}{ PTAR } & \multirow{3}{*}{ Nitrógeno Total (\%) } & \multirow{3}{*}{ Fósforo (\%) } & \multirow{3}{*}{ Potasio (\%) } & \multicolumn{2}{|c|}{ Parámetros } & \multirow{3}{*}{ Materia Orgánica (\%) } & \multirow{3}{*}{ Sólidos Totales (\%) } \\
\hline & & & & & & & \\
\hline & & & & $10 \%$ & $20 \%$ & & \\
\hline San Juan & 1.20 & 0.0005 & 0.11 & 6.78 & 6.94 & 37.94 & --- \\
\hline Julio C. Tello & 4.67 & 2.1100 & 0.1281 & 6.60 & 6.90 & 37.33 & --- \\
\hline Cieneguilla & 5.52 & 0.2500 & 0.1518 & 7.60 & 8.40 & 44.24 & --- \\
\hline Ancón & 1.965 & 0.0583 & 1.29 & 6.30 & 7.30 & 31.16 & ---- \\
\hline Ventanilla & 37.05 & 0.0900 & 0.052 & 5.29 & 5.45 & 42.70 & 93.10 \\
\hline Huáscar & 2.81 & 0.2271 & 1.379 & 7.10 & 7.40 & 57.65 & --- \\
\hline José Gálvez & 1.03 & 2.421 & 1.47 & 7.50 & 8.00 & 61.62 & --- \\
\hline $\begin{array}{l}\text { Compost obtenido en la Planta de } \\
\text { Pampamarca Chico - Carhuaz }\end{array}$ & $>0.6$ & $>0.5$ & $>0.3$ & 5.00 & 8.00 & $>30.0$ & \\
\hline
\end{tabular}

Fuente: Elaboración propia.

Tabla 7. Caracterización de lodos considerando valor energético

\begin{tabular}{lccccc}
\hline $\begin{array}{l}\text { Parámetros } \\
\text { PTAR }\end{array}$ & $\begin{array}{c}\text { Humedad } \\
(\%)\end{array}$ & $\begin{array}{c}\text { Materia Volátil } \\
(\%)\end{array}$ & $\begin{array}{c}\text { Cenizas } \\
(\%)\end{array}$ & $\begin{array}{c}\text { Carbono } \\
\text { Fijo (\%) }\end{array}$ & $\begin{array}{c}\text { Poder Calorífico (*) } \\
(\text { Kcal/Kg) }\end{array}$ \\
\hline San Juan & 12,33 & 38,11 & 46,00 & 15,89 & 4902,254 \\
Ventanilla & 10,55 & 37,51 & 45,64 & 12,85 & 5159,100 \\
\hline
\end{tabular}

Fuente: Elaboración propia. ( $\left.{ }^{*}\right)$ Aplicando formula de Gouthal 


\subsection{Valor comercial de los lodos}

\subsubsection{Fertilizante}

Los resultados de la encuesta para medir el uso con fines agrícolas se anotan a continuación:

- El $62 \%$ de la población encuestada no estaba informado acerca de la utilización del lodo, sin embargo, un $74 \%$ de la población encuestada considera algo positivo la introducción de este nuevo producto al mercado.

- Un $76 \%$ de la población encuestada indico que utilizaría este nuevo producto para fertilizar la tierra ya que en su mayoría se dedican a la siembra de chala, plantas ornamentales, maíz, etc.

- De la población encuestada el 38\% considera que si necesitaran de este nuevo producto. Por otro lado, un 5\% menciono que definitivamente no le es necesario ya que se dedican a la cría de animales que es su fuente principal de ingreso.

- En cuanto la relación calidad-precio el 67\% de la población encuestada coincide en que el precio es promedio con respecto a los productos que utilizan. Mientras que un $21 \%$ indico que está por encima del promedio.

- De la población encuestada el $43 \%$ tiene la intención de adquirir el producto para probarlo si ya estuviera a la venta, caso contrario un $2 \%$ no tiene intención de adquirirlo.

- Un $43 \%$ de la población encuestada menciona que es algo probable que puedan reemplazar el producto que actualmente utilizan por este nuevo producto, siempre y cuando le dé mejores resultados en cuanto a rendimiento y efectividad que el producto que actualmente utilizan. Mientras que el 5\% considera que no reemplazaría el producto por temor y desconocimiento de los lodos generados en una Planta de Tratamiento de Aguas Residuales (Falcón Roque, 2005).

- $\quad$ El $57 \%$ de la población encuestada menciona que es algo probable que recomiende el nuevo producto, después de corroborar su efectividad. Mientras que, un $2 \%$ índico que no recomendaría un producto que no va a utilizar.

- De la población encuestada el $45 \%$ considera que el nuevo producto sería muy novedoso. Por otro lado, el $5 \%$ indico que no le es novedoso porque ya habían escuchado antes el mencionado producto.

\subsubsection{Energético}

Los resultados de la encuesta para medir el uso con fines energéticos se anotan a continuación:

- $\quad$ El 33.3\% de las empresas encuestada considera muy positivo este nuevo producto, mientras que otro $33.3 \%$ se mantiene neutral con respecto a este nuevo producto.

- De las empresas encuestada el 33.3\% considera que si es probable que necesite de este nuevo producto. Por otro lado, un $33.3 \%$ menciono que definitivamente no es necesario.

- El $66.7 \%$ no tiene la intención de adquirir el producto si ya estuviera a la venta, de igual manera un $33.3 \%$ indica que no es tan probable adquirir el nuevo producto.

- Un $33.3 \%$ de las empresas encuestada menciona que es extremadamente probable que se pueda reemplazar el producto que actualmente utilizan por un nuevo producto. Mientras que el 33.3\% considera que no reemplazaría el producto.

- De las empresas encuestadas el 33.3\% menciona que es muy probable que recomiende el nuevo producto. Mientras que otro $33.3 \%$ indico que no es tan probable que recomiende dicho producto.

- $\quad$ El 33.3\% considera que el nuevo producto sería muy novedoso. Por otro lado, el $33.3 \%$ indico que no es novedoso.

- Los tipos de fuente energía utilizados por las empresas encuestadas son Energía Eléctrica (48 Kwh/ tonelada cemento), Carbón Bituminoso (180 000 t/año) y Gas Natural.

- El costo económico anual que genera el uso de fuentes de energía para las empresas encuestadas varía entre $\mathrm{S} / 4^{\prime} 900,000.00$ a los $\mathrm{S} / 21^{\prime} 000,000.00$ aproximadamente.

\section{DISCUSIÓN}

\subsection{Indicadores operativos}

Determinar el tipo de tratamiento actual de lodos es importante ya que nos permite medir el esfuerzo que conllevará el potenciar el tratamiento de lodo crudo. Al respecto, se utiliza mayormente el secado físico por acción solar lo cual es menos efectivo dado el clima predominante en Lima Metropolitana y que implica mayor humedad del lodo. La deshidratación por centrifugación es más efectiva por lo que se deberá considera éste como tratamiento de secado de lodos.

La relación lodo/agua, que nos permite determinan la efectividad del tratamiento de aguas residuales respecto a la generación de lodos. Era previsible que en la PTAR San Juan se genere la mayor cantidad de lodos, por el volumen de agua residual tratada y en empleo de lagunas aireadas. En general los sistemas aireados de tratamiento de aguas residuales tienen dicho inconveniente dado que las bacterias no tienen el tiempo suficiente para digerir el lodo generado. La ventaja es que generan cantidades mucho menores de gases malolientes. 
Respecto a la relación área/personal, la cantidad de personal operativo en las 7 PTAR muestra varía aproximadamente de 1 a 5 hectáreas/operador. Lo recomendado por Oakley \& Salguero es de 4 a 8 hectáreas por operador, en consecuencia, aparte de la PTAR San Juan, las otras PTAR tienen déficit de personal (SUNASS, 2015). Cabe resaltar además que en ninguna de las PTAR existe personal específico para el manejo de lodos; dependiendo de la tecnología de tratamiento de lodos este personal se estima debe variar entre 1 a 3 personas (Andreoli et al., 2007). La mayoría de operadores de las PTAR tienen nivel de instrucción básico (secundaria) pero no han tenido formación técnica, los operadores recibieron capacitación técnica en EPS donde laboran o mediante cursos externos, cabe mencionar que el año 2014 se publicó la Resolución Ministerial $\mathrm{N}^{\circ}$ 273-2013-VIVIENDA que exige la presentación de un informe descriptivo de las PTAR en operación y que implica el requerimiento de capacitación de dicho personal.

\subsection{Calidad de los lodos}

Considerando los LMP de parámetros metálicos y biológicos contenidos en la norma mexicana, EPA y peruana, se puede señalar lo siguiente:

\subsubsection{PTAR Ancón}

Presenta buena calidad en cuanto a concentraciones metálicas y contenidos biológicos pudiendo usarse para: fines forestales, mejoramiento de suelos, usos agrícolas (según la norma mexicana); recuperación de suelos, plantaciones forestales, consumos no directos, cobertura de rellenos sanitarios (según EPA); y con restricciones sanitarias (según norma peruana).

\subsubsection{PTAR Cieneguilla}

Presenta buena calidad en cuanto a concentraciones metálicas y contenidos biológicos, las 3 normas concluyen que se pueden usar para algún fin tal como los lodos de la PTAR Ancón.

\subsubsection{PTAR Huáscar}

La calidad metálica de estos lodos es buena, pero los contenidos biológicos exceden en el parámetro Coliformes Termotolerantes. Según Andreoli et al. (2007), se pueden conseguir remover hasta con una eficiencia de $99,9 \%$ este parámetro biológico mediante la aplicación de un oxidante fuerte, como el ozono, que aparte tiene la ventaja de inactivar con relativa facilidad gérmenes muy resistentes como virus, Legionella, Pseudomona aeruginosa, Entamoeba histolytica, quistes de Giardia, Crystosporidium parvum y Mycobacterium.

\subsubsection{PTAR José Gálvez}

Presenta buena calidad en cuanto a concentraciones metálicas y contenidos biológicos, las 3 normas concluyen que se pueden usar para algún fin tal como los lodos de la PTAR Ancón.

\subsubsection{PTAR Julio C. Tello}

Hay concentraciones contradictorias de Cadmio existente en los lodos de la PTAR Julio C. Tello, 136 mg/kg (2015) y $1,25 \mathrm{mg} / \mathrm{kg}$ (2019), por lo que la recomendación es que se analicen nuevas muestras. Según Andreoli et al. (2007) mediante la aplicación del vermicomposteo, utilizando lombrices de la especie Eisenia fétida, se puede reducir la concentración de Cadmio con una eficiencia de hasta 95 $\%$. Respecto a contenidos biológicos, se concluye que se pueden usar para: fines forestales, mejoramiento de suelos, usos agrícolas (según la norma mexicana); recuperación de suelos, plantaciones forestales, consumos no directos, cobertura de rellenos sanitarios (según EPA); y con restricciones sanitarias (según norma peruana).

\subsubsection{PTAR San Juan}

En la PTAR San Juan es la concentración de Zinc existente en los lodos, $3257 \mathrm{mg} / \mathrm{kg}$ (2015) y $3750 \mathrm{mg} / \mathrm{kg}$ (2019) y de Coliformes Termotolerantes, 3.67x $10^{5} \mathrm{NMP} / \mathrm{g}$ (2015) y $3.67 \times 10^{4} \mathrm{NMP} / \mathrm{g}$ (2019), lo que los inhabilita para cualquier uso según la norma EPA y la norma peruana, pero según la norma mexicana si puede usarse para usos urbanos sin contacto público directo durante su aplicación. Según Andreoli et al. (2007), la interacción entre una cantidad del alcalinizante $\mathrm{NaOH}$ y la cantidad del coagulante $\mathrm{FeCl}_{3}$ tienen incidencia significativa en el proceso de la remoción del Zinc, llegando a obtenerse una eficiencia de 99,90\%. Para la remoción de Coliformes Termotolerantes se debe seguir el procedimiento descrito para la PTAR Huáscar y que recomienda el mismo autor.

\subsubsection{PTAR Ancón}

Presenta buena calidad en cuanto a concentraciones metálicas y contenidos biológicos pudiendo usarse para: fines forestales, mejoramiento de suelos, usos agrícolas (según la norma mexicana); recuperación de suelos, plantaciones forestales, consumos no directos, cobertura de rellenos sanitarios (según EPA); y con restricciones sanitarias (según norma peruana).

\subsection{Calidad comercial de los lodos}

Respecto a nitrógeno, todos los lodos presentan valores arriba del que tiene el compost de Huaraz; en cuanto al fósforo: solo los lodos de las PTAR Julio C. Tello y José Gálvez presentan valores mayores; en cuanto a contenidos de potasio: los lodos de las PTAR Ancón, Huáscar y José Gálvez están por encima; los valores de $\mathrm{pH}$ están mayormente dentro del rango de 5 a 8, a excepción del lodo generado en la PTAR Cieneguilla que excede ligeramente; con respecto a materia orgánica, todos los lodos presentan valores mayores del $30 \%$ que tiene el compost de Huaraz .

En la Tabla 2, se observa que el poder calorífico de los lodos de las 2 PTAR caracterizadas son lo suficientemente alto como para que su valoración energética por incineración sea viable. Sin embargo, debido a la elevada humedad que contiene al salir del secado físico, su transporte encarecería mucho el proceso. Por tanto, es recomendable un secado térmico previo a su transporte hacia la planta incineradora, dado que el secado térmico permite eliminar la mayor parte 
de agua intracelular de los lodos mediante la aplicación de calor externo. El producto del secado mantiene su contenido en material sólido y su humedad queda reducida a un $10-15 \%$. Por tanto, es aconsejable realizar este proceso en la misma planta o cerca.

\subsection{Valor comercial de lodo}

\subsubsection{Fertilizante}

Según Dáguer (2007), el valor del contenido de nitrógeno en el lodo de las lagunas de estabilización se estima en aproximadamente S/. 0,1 por kilo de lodo seco, y por su contenido de fosforo se estima en aproximadamente $\mathrm{S} /$. 0,01 por kilo de lodo seco, en ambos casos sin considerar el traslado del lodo hacia las áreas verdes. Este resulta un costo atractivo considerando que en el mercado el valor de un fertilizante mineral, como nitrato de amonio, es de aproximadamente S/. 4,6 por kilo de nitrógeno y el precio del fertilizante mineral, como roca fosfórica, es de aproximadamente $\mathrm{S} / .7$ a 8 por kilo de fosforo.

Por parte de la demanda, el resultado concreto es que existe un mercado potencial para el uso de lodo tratado para fertilizar tierras de cultivo, se recalca que ya se está usando, aunque informalmente. Lo que falta es más difusión respecto a la calidad del lodo crudo actual y la potencialidad que tendría ya tratado para usarlo con fines agrícolas. Obviamente la población es reticente a su uso formal por la percepción que tienen de que contiene residuos peligrosos.

\subsubsection{Energético}

La apreciación general respecto al uso energético es que hay un interés incipiente del uso del desecho lodo como fuente de energía no renovable y que faltaría mayor promoción para posibilitar una mayor acogida.

\subsection{Innovación en la gestión}

La muestra considerada en el trabajo de investigación, lodos crudos generados en 7 PTAR, representa $2538 \mathrm{Tn}$ / día de lodos que SEDAPAL gestiona solo contratando a una empresa operadora de residuos sólidos que se encarga de almacenarlos en contenedores, transportarlos y disponerlos en rellenos sanitarios existentes en la ciudad de Lima, a un costo promedio diario de S/ 248,724. De la evaluación realizada se resume que: a) los lodos crudos no son de mala calidad y, a bajo costo, se pueden convertir en un insumo que pueda utilizarse con fines agrícolas o energéticos, c) tienen un valor nutricional inherente que puede ser explotado, c) existe un mercado potencial insipiente para su uso con fines agrícolas y también hay interés para su uso con fines energéticos. Pero el tratarlos y comercializarlos requiere recursos económicos que se pueden conseguir modificando la gestión actual de los lodos crudos. Ya como insumo se podrá generar, con el tiempo, rentabilidad a la empresa.

\section{CONCLUSIONES}

- La innovación de este trabajo de investigación se sustenta en el enfoque sistémico de este negocio ambiental, comercialización del lodo tratado, dentro del marco de integración de la economía, el trabajo y el derecho. Según Onyeche (2007), representa una nueva forma de hacer negocios verdes, entendidos esto como aquellos que reducen el impacto ambiental por parte de los sectores económicos con el objetivo de lograr niveles sostenibles. Es obvio que se requiere una innovación respecto a cómo se gestionan actualmente, ya que se requiere tratar, enriquecer y comercializar el lodo crudo generado en las 7 PTAR, $2538 \mathrm{Tn} /$ día, a fin de incorporarlo a la cadena de valor.

- Delacaracterización ambiental de los lodos crudos, es decir la comparación entre sus contenidos y las normas de calidad del lodo mexicana, EPA y peruana, se obtiene que mayormente son de buena calidad y el esfuerzo por mejorarlos implicaría reducir las concentraciones de cadmio, zinc y coliformes termotolerantes; cabe resaltar que existe actualmente tecnologías que posibilitaría reducir la concentración de estos tres elementos señalados, a bajo costo y con alta eficiencia. En un análisis bacteriológico según las 3 norma, los lodos de las PTAR Ancón, Cieneguilla, José Gálvez y Ventanilla pueden tener usos forestales, agrícolas y como mejoradores de suelos.

- De las evaluaciones realizadas con la finalidad de establecer el contenido nutricional de los lodos crudos, queda demostrado que éstos tienen mejor calidad, en cuanto a nitrógeno total, materia orgánica y $\mathrm{pH}$, que el compost que se elabora en la Planta de Pampamarca Chico-Carhuaz-Huaraz (Perú). Solo se requeriría enriquecer el lodo en cuanto a contenidos de fósforo y potasio.

- Se realizaron dos encuestas con la finalidad de establecer la capacidad de acogida que podría tener este desecho ya convertido en un insumo. Respecto a su uso como fertilizante, existe población que estaría interesado en su demanda siempre que se mejore la calidad vía tratamiento y/o enriquecimiento; es más, ya existe un uso informal del mismo. En relación a fines energéticos, la demanda es incipiente y está sujeta básicamente a una mayor difusión del uso para este fin.

\section{REFERENCIAS}

Andreoli, C. V., Von Sperling, M., \& Fernandes, F. (2007). Sludge Treatment and Disposal. In Biological Wastewater Treatment series. http://iwaponline.com/ebooks/bookpdf/1984/wio9781780402130.pdf

CONAM. (2006). Guía Técnica para la Formulación $e$ Implementación de Planes de Minimización y Reaprovechamiento de Residuos Sólidos en el nivel Municipal. 100. https://sinia.minam.gob.pe/documentos/ guia-tecnica-formulacion-implementacion-planesminimizacion

Dáguer, G. P. (2007). Gestión de Biosólidos de la PTAR El Salitre [Universidad Javeriana. Colombia]. https://docplayer. es/21537313-Gestion-de-biosolidos-en-colombia.html 
Falcón Roque, E. J. (2005). PRODUCCIÓN DE COMPOST A PARTIR DE LOS LODOS GENERADOS EN LA PLANTA DE TRATAMIENTODEAGUASRESIDUALESCOVICORTIDE SEDALIB S.A. TRUJILLO [Universidad Nacional Agraria La Molina, Lima (Peru). Facultad de Ingeniería Agrícola.]. http://www.sidalc.net/cgi-bin/wxis.exe/?IsisScript=tesispe. $\mathrm{x}$ is $\&$ method $=$ post $\&$ formato $=2 \&$ cantidad $=$ 1 \&expresion $=\mathrm{mfn}=002381$

Onyeche, T. (2007). Economic benefits of low pressure sludge homogenization for wastewater treatment plants. Specialist Conferences. Moving Forward Wastewater ..., 1, 417-422. https://www.semanticscholar.org/paper/ Economic-benefits-of-low-pressure-sludge-for-plantsOnyeche/ba5f7e0ea1b28992f2a77865a4a9261665055a23\# paper-header
SUNASS. (2015). Diagnóstico de las plantas de tratamiento de aguas residuales en el ámbito de operación de las entidades prestadoras de servicios de saneamiento. Depósito Legal En La Biblioteca Nacional Del Perú No 2015-16066, I, 150. www.proagua.org.pe

\section{ANEXOS}

Anexo 1: Fichas encuesta para fines de uso agrícola y energéticos

\section{Encuesta: Uso con Fines Agrícolas}

Servicio ofrecido a futuro: venta de lodo seco proveniente de PTARs

de origen doméstico para diferentes usos. Costo estimado $=\mathrm{S} / .0 .01 / \mathrm{Kg}$.

Tiene el mismo potencial que los fertilizantes comerciales

1. ¿Cuál es su primera reacción respecto a este nuevo producto?
a) Muy positivo
b) Algo positivo
c) Neutral
d) Algo negativo
e) Muy negativo

2. ¿Para qué lo utilizaría?
a) Fertilizar tierras
b) Restaurar suelos
c) Insumo de materiales de construcción
d) Cobertura de residuos sólidos (basuras)
e) Otros:

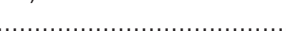

3. ¿Cuál considera es el grado de innovación de este producto?
a) Muy innovador
b) algo innovador
c) No es tan innovador
d) No del todo innovadora

4. ¿Considera que este producto es algo que necesita o no le es necesario?
a) Sin duda necesito
b) Probablemente necesitare
c) No opino
d) Probablemente no es necesario
e) Definitivamente no es necesario

5. ¿Cómo calificaría la relación calidad-precio del producto?
a) Excelente
b) Por encima de la media
c) Promedio
d) Por debajo del promedio
e) Pobre

6. Si él producto estuviera disponible en la actualidad, ¿qué probabilidad existe de que compre este nuevo producto?
a) Extremadamente probable
b) Muy probable
c) Algo probable
d) No es tan probable
e) Nada probable
c) Algo probable
a) Extremadamente probable
b) Muy probable
e) Nada probable

8. ¿Qué tan probable es que usted recomiende nuestro nuevo producto a un amigo o colega?
a) Nada Probable
b) Algo probable
c) No es tan probable
d) Muy probable

9. En sus propias palabras, ¿Cuáles son las cosas que lo atraen más de este nuevo producto?

10. En sus propias palabras, ¿Cuáles son las cosas que más le gustaría mejorar en este nuevo producto? 


\section{Encuesta: Uso con Fines Energéticos}

En el marco del trabajo de investigación que viene desarrollando el Mg. José Jorge Espinoza Eche se ha caracterizado los lodos que se generan en siete (7) Plantas de Tratamiento de Aguas Residuales administradas por SEDAPAL y se ha encontrado que tanto los contenidos metálicos como bacteriales se encuentran por debajo de los límites máximo permisibles establecidos por la EPA. Por ello el siguiente paso fue determinar su potencialidad tanto para uso como ayudador de fertilidad de suelo como para fines energéticos. Respecto a esto último, estos lodos tienes una capacidad calorífica mayor a $4500 \mathrm{Kcal} / \mathrm{Kg}$ lo que implica una aceptable valoración energética. Son 926 315,19 Tm/año de lodos, aproximadamente 899335,13 mªño, que se pueden aprovechar con esta finalidad. Con ello el objetivo que propone es que el lodo pase a convertirse de un problema ambiental a un producto negociable, por lo que como servicio ofrecido a futuro necesitamos nos apoyen en este Estudio de Mercado respondiendo las preguntas que a continuación se señalan:

1. ¿Cuál es su primera reacción respecto a este nuevo producto?
a) Muy positivo
b) Algo positivo
c) Neutral
d) Algo negativo
e) Muy negativo
c) No opino
a) Sin duda necesito
necesita o no le es necesario?
d) Probablemente no es necesario
b) Probablemente necesitaré
e) Definitivamente no es necesario

3. Si él producto estuviera disponible en la actualidad, ¿qué probabilidad existe de que compre este nuevo producto?
a) Extremadamente probable
b) Muy probable
c) Algo probable
d) No es tan probable
e) Nada probable
c) Algo probable

4. ¿Qué tan probable es que reemplace el producto que actualmente usa?
a) Extremadamente probable
b) Muy probable
c) Algo probable
d) No es tan probable
e) Nada probable

5. ¿Qué tan probable es que usted recomiende nuestro nuevo producto?
a) Nada Probable
b) Algo probable
c) No es tan probable
d) Muy probable

6. ¿Qué tan novedoso considera que sería el lanzamiento de este nuevo producto?
a) Extremadamente novedoso
b) Muy novedoso
c) Algo novedoso
d) No es tan novedoso
e) Nada novedoso

7. ¿Qué fuente de energía utiliza y en qué cantidad?

8. ¿Cuál es el costo económico anual que le genera el uso de dicha fuente de energía?

Respondidas estas 2 últimas preguntas les haremos llegar la cuantificación de $\mathrm{CO}_{2}$ que probablemente emiten sus Plantas.

Anexo 2. Normas de calidad de lodos crudos y tratados

Tabla 1. Límites Máximos Permisibles para biosólidos

\begin{tabular}{|c|c|c|c|c|c|c|}
\hline \multirow{2}{*}{$\begin{array}{l}\text { Parámetros } \\
\text { físico químicos }\end{array}$} & \multirow{2}{*}{ Unidad } & \multicolumn{2}{|c|}{ Norma Mexicana } & \multirow{2}{*}{ Norma EPA } & \multirow{2}{*}{\multicolumn{2}{|c|}{ D.S. N N 015-2017-Vivienda }} \\
\hline & & Excelente & Bueno & & & \\
\hline Arsénico & $\mathrm{mg} / \mathrm{Kg}$ & 41 & 75 & 41 & \multicolumn{2}{|c|}{40} \\
\hline Cadmio & $\mathrm{mg} / \mathrm{Kg}$ & 39 & 85 & 39 & \multicolumn{2}{|c|}{40} \\
\hline Cromo & $\mathrm{mg} / \mathrm{Kg}$ & 1200 & 3000 & No regulado & \multicolumn{2}{|c|}{1200} \\
\hline Cobre & $\mathrm{mg} / \mathrm{Kg}$ & 1500 & 4300 & 1500 & \multicolumn{2}{|c|}{1500} \\
\hline Mercurio & $\mathrm{mg} / \mathrm{Kg}$ & 17 & 57 & 17 & \multicolumn{2}{|c|}{17} \\
\hline Molibdeno & $\mathrm{mg} / \mathrm{Kg}$ & -- & - & - & \multicolumn{2}{|c|}{-} \\
\hline Níquel & $\mathrm{mg} / \mathrm{Kg}$ & 420 & 420 & 420 & \multicolumn{2}{|c|}{400} \\
\hline Plomo & $\mathrm{mg} / \mathrm{Kg}$ & 300 & 840 & 300 & \multicolumn{2}{|c|}{400} \\
\hline Selenio & $\mathrm{mg} / \mathrm{Kg}$ & -- & - & 100 & \multicolumn{2}{|c|}{-} \\
\hline Zinc & $\mathrm{mg} / \mathrm{Kg}$ & 2800 & 7500 & 2800 & \multicolumn{2}{|c|}{2400} \\
\hline $\begin{array}{c}\text { Parámetros } \\
\text { microbiologicos }\end{array}$ & \multicolumn{2}{|c|}{ Unidad } & Norma Mexicana & \multicolumn{2}{|c|}{ Norma EPA } & D.S. N ${ }^{\circ} 015-2017-V i v i e n d a$ \\
\hline Coliformes Totales $\left(35^{\circ} \mathrm{C}\right)$ & & $\mathrm{MP} / \mathrm{g}$ & - & & - & - \\
\hline $\begin{array}{l}\text { Coliformes Termotolerantes } \\
\left(44,5^{\circ} \mathrm{C}\right)\end{array}$ & & D/100g & 2000000 & & $\begin{array}{l}0000 \text { Clase B } \\
000 \text { Clase A }\end{array}$ & - \\
\hline Huevos Helminto & & evos/g & $<35$ & & $\begin{array}{l}1 \text { Clase B } \\
1 \text { Clase A }\end{array}$ & $<1 / 4 \mathrm{~g}$ ST Clase A \\
\hline Quistes de Protozoarios & & stes/g & - & & - & - \\
\hline Salmonella & & $\mathrm{MP} / \mathrm{g}$ & $<300$ & & - & $<1 \mathrm{NMP} / 10 \mathrm{~g}$ ST Clase A \\
\hline Cryptosporidiumsp & & istes/mg & - & & - & - \\
\hline
\end{tabular}


Tabla 2. Límites Máximos Permisibles para patógenos y parásitos en Lodos y Biosólido

\begin{tabular}{cccc}
\hline Clase & $\begin{array}{c}\text { Indicador Bacteriológico de Contaminación } \\
\text { Coliformes fecales NMP/g en base seca }\end{array}$ & $\begin{array}{c}\text { Patógenos } \\
\text { Salmonella spp. NMP/g en base seca }\end{array}$ & $\begin{array}{c}\text { Parásitos } \\
\text { Huevos de helmintos/g en base seca }\end{array}$ \\
\hline A & Menor de 1000 & Menor de 3 & Menor de 1(a) \\
B & Menor de 1000 & Menor de 3 & Menor de 10 \\
C & Menor de 2000000 & Menor de 300 & Menor de 35 \\
\hline
\end{tabular}

Fuente: Norma Oficial Mexicana NOM-004-SEMARNAT-2002

Notas. - (a) Huevos de helmintos viables NMP: número más probable

Tabla 3. Aprovechamientos de Biosólidos

\begin{tabular}{|c|c|c|}
\hline Tiро & Clase & Aprovechamiento \\
\hline Excelente & A & $\begin{array}{l}\text { - Usos Urbanos, sin contacto público directo durante su aplicación. } \\
\text { - Los establecidos para clase B y C. }\end{array}$ \\
\hline Excelente o Bueno & B & $\begin{array}{l}\text { - Usos Urbanos, sin contacto público directo durante su aplicación. } \\
\text { - Los establecidos para clase C. }\end{array}$ \\
\hline Excelente o Bueno & C & $\begin{array}{l}\text { Usos Forestales. } \\
\text { : Usjoramientos de Suelos. }\end{array}$ \\
\hline
\end{tabular}

Fuente: Norma Oficial Mexicana NOM-004-SEMARNAT-2002

Tabla 4. Aprovechamientos de Biosólidos

\begin{tabular}{|c|c|}
\hline Clase & Aprovechamiento \\
\hline A & - Pueden ser usados sin ninguna restricción (consumo directo) \\
\hline B & $\begin{array}{l}\text { - Recuperación de suelos. } \\
\text { - Plantaciones forestales. } \\
\text { - Consumos no directos. } \\
\text { - Cobertura de rellenos sanitarios. }\end{array}$ \\
\hline
\end{tabular}

Tabla 5. Calidad del compost obtenido en la Planta de Pampamarca Chico - Carhuaz

\begin{tabular}{|c|c|c|c|c|c|c|c|}
\hline \multirow{3}{*}{ Planta } & \multicolumn{7}{|c|}{ Parámetros } \\
\hline & \multirow[b]{2}{*}{ Nitrógeno Total (\%) } & \multirow[b]{2}{*}{ Fósforo (\%) } & \multirow[b]{2}{*}{ Potasio (\%) } & \multicolumn{2}{|c|}{$\mathrm{pH}$} & \multirow[b]{2}{*}{ Materia Orgánica (\%) } & \multirow{2}{*}{ Sólidos Totales $(\%$} \\
\hline & & & & $10 \%$ & $20 \%$ & & \\
\hline Compostaje y lombricompostaje & $>0.6$ & $>0.5$ & $>0.3$ & 5.00 & 8.00 & $>30.0$ & --- \\
\hline
\end{tabular}

Fuente: CONAM, 2006: Guía Técnica para la formulación e implementación de planes de minimización y reaprovechamiento de residuos sólidos en el nivel municipal. 